Article

\title{
Flying Less for Work and Leisure? Co-Designing a City-Wide Change Initiative in Geneva
}

\author{
Marlyne Sahakian ${ }^{1, *}$, Malaïka Nagel ${ }^{1}$, Valentine Donzelot ${ }^{1}$, Orlane Moynat ${ }^{1}$ and Wladyslaw Senn ${ }^{2}$ \\ ${ }^{1}$ Institute of Sociological Research, University of Geneva, 1204 Geneva, Switzerland; \\ E-Mails: marlyne.sahakian@unige.ch (M.S.), malaika.nagel@etu.unige.ch (M.N.), valentine.donzelot@etu.unige.ch (V.D.), \\ orlane.moynat@unige.ch (O.M.) \\ 2 Terragir Association, 1217 Meyrin, Switzerland; E-Mail: wladyslaw.senn@terragir.ch \\ * Corresponding author
}

Submitted: 11 December 2020 | Accepted: 2 March 2021 | Published: 9 June 2021

\begin{abstract}
Geneva prides itself on being an international city, home to the United Nations and international organizations. The airport plays an important role in this image, tied to a quest for hypermobility in an increasingly globalized society. Yet, mobility accounts for close to one quarter of the territory's carbon emissions, with flights responsible for $70 \%$ of these emissions. With recent legislation that includes ambitious targets for net zero carbon emissions by 2050 , the role of air travel can no longer be ignored. In 2020, a partnership was formed between the City, the University of Geneva, and a community energy association to explore the possibility of co-designing a city-wide change initiative, focused on reducing flights through voluntary measures. The team consulted with a variety of actors, from citizens who fly for leisure, to those who fly for professional reasons, with a spotlight on academic travel. A review of the scientific and grey literature revealed what initiatives already exist, leading to a typology of change initiatives. Inspired by this process, we then co-designed a series of workshops on opportunities for flying less in Geneva. We demonstrate the value of going beyond an 'individual behaviour change' approach towards understanding change as embedded in socio-material arrangements, as well as identifying interventions that seek to address both negative and positive anticipated outcomes. We conclude with insights on how a social practice approach to understanding mobility reveals both material and immaterial challenges and opportunities, involving infrastructures and technologies, but also social norms and shared meanings.
\end{abstract}

\section{Keywords}

co-design; flying less; Geneva; participative methods; social practices; Switzerland

\section{Issue}

This article is part of the issue "Cities, Long-Distance Travel, and Climate Impacts" edited by Jukka Heinonen (University of Iceland, Iceland) and Michał Czepkiewicz (University of Iceland, Iceland / Adam Mickiewicz University in Poznań, Poland).

(C) 2021 by the authors; licensee Cogitatio (Lisbon, Portugal). This article is licensed under a Creative Commons Attribution 4.0 International License (CC BY).

\section{Introduction}

Air travel is increasingly recognized as having a significant environmental impact, in terms of carbon emissions and equivalents (Ritchie, 2020) while being a form of transport that is unevenly distributed-only 2 to $3 \%$ of the world's population flies each year (Nevins, 2014; Peeters, Gössling, \& Becken, 2006). Among those that travel, urbanities show a higher disposition to be frequent flyers (Czepkiewicz, Árnadóttir, \& Heinonen, 2019).
In Geneva, mobility is responsible for $23 \%$ of all carbon emissions and equivalents in 2015 , with air travel counting for $70 \%$ of emissions in the mobility sector (State of Geneva, 2015). Prior to the outbreak of the Covid-19 pandemic, the Federal Office of Civil Aviation (OFAC) and Geneva Airport predicted a significant increase in numbers of passengers and flights by 2030 (OFAC, 2018). Indeed, there were almost 2,5 times more passengers departing from Geneva in 2019 than in 2000 (Federal Statistical Office [OFS], 2020). Switzerland also exhibits 
more air travel per capita than neighbouring countries, such as France or Germany (OFAC, 2018).

As home to the United Nations, Geneva prides itself on being an 'international city' and the airport contributes to this image, as a symbol of hypermobility in an increasingly globalized society (Harvey, 1990). At the same time, in light of the climate crisis and the mobilization of citizens around climate strikes, there is growing political will to reduce carbon emissions. In Switzerland as is the case elsewhere, a variety of campaigns have been launched-by policy-makers, institutions and associations, and individual citizens - to identify opportunities to reduce air travel, both for leisure and professional reasons. In this context and in the Summer of 2019, prior to the outbreak of the Covid-19 pandemic, the City of Geneva-Agenda 21-Sustainable city unit contacted the University of Geneva's Institute of sociological research to reflect on how the city could support a voluntary initiative to 'fly less' in 2021. The project was co-designed between a core team of people at the City, the University, and Terragir, a community association with expertise in energy transitions. The project reflects the role that municipalities and other actors can play at the urban level, to reduce the aviation emissions of city residents.

While the overall project aims to develop a better understanding of what might support or hinder a social change initiative towards flying less, we focus here on the collaborative, co-design process, as well as the theoretical framework which informs our understanding of complex problems. The article is structured as follows: first, we introduce the problem of air travel and the conceptual framework, or designing social change initiatives through social practice theory. Second, we present a review of 37 initiatives world-wide that aim towards reducing flights, for leisure or professional purposes, towards a typology of change initiatives. Third, we discuss the results of three multi-actor workshops on reducing flights, whereby impacts were identified in relation to different 'elements' of practice. We stop short of detailing the approach chosen by the City, as this process is still ongoing, but provide some indication of the preferred way forward. We conclude with a discussion on both the process and outcomes of this co-design effort.

\section{Literature Review, Conceptual Framework, and Methods}

\subsection{Why Flying Less Is a Complex Aim}

More affluent consumers are responsible for higher environmental impacts, not least due to forms of mobility based on fossil fuels, including air travel. The top $10 \%$ of the global population, also known as the 'consumption elite,' consume $55 \%$ of the energy resources allocated to mobility (Oswald, Owen, \& Steinberger, 2020). In Switzerland, people fly an average of 0,83 times a year, with a large difference between people with low incomes (0,3 times a year), high incomes (once per year) and very high incomes (1,7 times a year; OFS, 2017). The airplane represents an unequalled form of travel for some, in its ability to cover great distances in minimal time, and as a symbol of technical prowess, which adds to its symbolic qualities - as discussed by Harvey (1990) in relation to hypermobility and increased connectivity of people across spaces. While flying remains a luxury for many around the world today, a discourse analysis in Swedish magazines and media demonstrates how air travel evolved from a consumer good of desire or a dream to a generalized and normalized practice in the 1980s (Ullström, Nicholas, \& Stripple, 2020)-a more affluent country, similar to Switzerland. Analyses of aviation carbon emissions confirm the trend: "The cumulative emissions of global aviation (1940-2018) are 32.6 billion $\left(10^{9}\right)$ tonnes of $\mathrm{CO}_{2}$, of which approximately $50 \%$ were emitted in the last 20 years" (Lee et al., 2020, p. 4). In Sweden, 2017 is seen as a turning point, when the discourses on air travel and travel seem to converge towards a certain moralization around flights and appreciation of a slower lifestyle and reduced carbon footprints (Ullström et al., 2020)-a similar trend has not yet been documented in the Swiss case.

Mobility is not only a question of movement, but also something useful, such as a capacity for action in a geographical and social space, what sociologist Vincent Kaufmann has termed 'motility' (Kaufmann, 2003). This capacity for action is particularly significant in the city of Geneva, which positions itself as an 'international' city and sees the airport as aligned with other symbols of this status, such as the United Nations headquarters. Global cities have developed in conjunction with the development of the aviation sector, which allows hyperconnectivity, creating a network on which these cities depend to remain competitive on a global scale. Certain urban planning models articulate the city around the airport, referred to as aerotropolises (Chohan, 2019). This capacity to move by airplane relates to a growing leisure industry; thus, travel facilitates consumption, understood as the appropriation and appreciation of spaces and experiences (Warde, 2017). In a consumer society, messages conveyed by the media but also through social networks seem to glorify flight travel-leading to a 'tourist's gaze' captured through shared photos, postcards, or other souvenirs (Urry \& Larsen, 2011), the cumulation of which is facilitated through air travel. People living in urban areas are embedded in global social networks; they also fly more because they generally have higher incomes, are mostly single and non-parents, have language skills related to their increased mobility, and seek to escape the city either to compensate for the lack of nature or for acquiring new cultural experiences (Czepkiewicz et al., 2019). Flying as a form of 'motility' is thus powered by high aspirations around air travel and an imagined network of 'global citizens' who pursue professional and leisure ambitions through the (over)consumption of spaces, making the reductions of flights a challenge. 
To add to this complexity, the travel market can be divided into two segments: travel for work, or travel for leisure. In the world of work, travel is often synonymous with success, towards maintaining networks and supply chain relations, for example. In $2018,63 \%$ of all flights from Switzerland were for leisure purposes, up $10 \%$ from 2017 . This was followed by flights for visiting close friends or relatives (25\%). Professional trips represented only $6 \%$ of all flights, half of which were for flights within Switzerland (OFS, 2019). As these figures only represent trips with overnight stays, the portion of day trips for professional reasons is under-estimated. In academia and in a globalized knowledge economy, flying is one way of maintaining international networks. Studies on the Swiss case are lacking, but for Sweden, Burian (2018) notes that one in two Swedish academics believe that carrying out research would be impossible without flying, thus hindering their careers. From an organizational perspective, possibilities for change within universities is significant, when such entities have a clear independence from the market-moving beyond voluntary travel policies, towards changing academic standards, and supporting adequate alternatives (Burian, 2018). Travel for professional reasons (in the public or private sector, including academic travel, or for nongovernmental organizations) is thus built around a model of success that can be questioned, in relation to climate change as well as health and wellbeing (Cohen, Hanna, \& Gössling, 2017; Espino, Sundstrom, Frick, Jacobs, \& Peters, 2002; Ivancevich, Konopaske, \& DeFrank, 2003). Regarding leisure travel, the environmental impact of flying and the un-sustainable nature of some forms of tourism are garnering attention in research and general press. Links between travel and wellbeing or selfdevelopment are equally emphasized (Hall, Gössling, \& Scott, 2015). While 'sustainable tourism' is a growing field of research and practice, the negative impacts of tourism on the climate do not seem to be decreasing (Peeters, 2016; Scott, Gössling, \& Hall, 2012), no doubt bolstered by low-cost air travel.

Büchs (2017) offers us a typology of people more or less inclined to reduce holiday flights, suggesting that values and norms are important when considering opportunities for change. For Randles and Mander (2009), understanding the moral dimension of flying or not flying is critical. And yet, Alcock et al. (2017) suggest that individuals who are more environmentally conscious tend to fly more kilometres per year than those who are not (no doubt due to the links between higher revenue, higher education, and travel, discussed above). This suggests an attitude-behaviour gap, revealing how people attempt to reconcile the actions they value, such as flying, with pro-environmental attitudes (Kroesen, 2013). Facing this complexity, it could be more effective to focus on changes in the aviation industry (such as financial or regulatory burdens), rather than inciting individuals to fly less, thus de-emphasizing the importance of consumer lifestyle choices (Kantenbacher,
Hanna, Cohen, \& Miller, 2018; Peeters, 2016). For Cohen, Higham, Gössling, Peeters, and Eijgelaar (2016), existing socio technical arrangements and infrastructure is what hinders attempts to reduce flying. In the same line, Larsson, Elofsson, Sterner, and Akerman (2019) outline existing (inter)national government-based policies and their effectiveness in relation to national measures, demonstrating the need to understand flying concomitantly at a global and local scale.

Flight travel for both professional reasons and leisure decreased dramatically during (semi-)confinement measures experienced around the world due to the outbreak of the Covid-19 pandemic. In terms of total energy, changes in demand were largest in the aviation sector, with a decrease in daily activity of $-75 \%$ ( -60 to $-90 \%)$ during confinement, although the sector contributed to only $10 \%$ of the decrease in global $\mathrm{CO}_{2}$ emissions (Le Quéré et al., 2020). Understanding how air travel can be reduced, once restrictions on mobility will be lifted, remains a pressing issue.

\subsection{Embedding Air Travel in Social Practices}

In sustainable consumption studies, there is a longstanding critique of the limits of individual approaches to change-whereby small actions, such as riding a bicycle and recycling, might render invisible the need for more structural and political change (Maniates, 2001) or where change is solely understood through green consumer scapegoatism (Akenji, 2014) rather than collective and transformative action (Balsiger, Lorenzini, \& Sahakian, 2019). Another approach that is critiqued in the literature is the idea that technologies will provide a silver bullet solution to un-sustainable practices (Cohen \& Murphy, 2001; Sahakian, 2019). Building on these insights, a review of over 1,000 initiatives focused on changing household energy usage in Europe revealed that a great majority (74\%) relied on either changing individual people's behaviour, or changing technologies (Jensen, Goggins, Røpke, \& Fahy, 2019). The authors stress the question of problem framing, which directly informs the types of solutions that are then proposed, contrasting changes in individual behaviour to more complex changes in everyday life.

A rapidly-growing body of literature in the social sciences has emerged in recent years, suggesting that social practices - rather than individual people or units of technology-should be the locus for change, as more representative of complexity. Building on earlier theoretical reflections by Bourdieu and Giddens, social practices focus on the doings and sayings of everyday life as a way to overcome the structure-agency dichotomy in social sciences (Schatzki, 1996). In such an approach, the focus is moved away from "cognitive and rationalist theories of action to embrace a theory of agency in which past experiences and the things with which the individual interacts are regarded as important to current and future actions" (Wilhite, 2016, p. 24). While there 
are different interpretations of what makes up a practice, approaches share an interest in practices-such as preparing a meal or planning a trip-as made up of different elements. Building on Shove and Pantzar (2005), these 'elements' involve interactions between skills and competencies, material arrangements and things (including technologies), and social norms and other meanings. Planning a trip involves all of these elements, which play out differently depending where and when the practice is performed.

While social practice theory has been used to understand how practices change over time (Sahakian \& Wilhite, 2014; Shove \& Pantzar, 2005), a growing body of work seeks to understand how social practices might inform policy and social change in the future (Devaney \& Davies, 2017; Jack, 2013; Sahakian \& Bertho, 2018; Spurling, McMeekin, Shove, Southerton, \& Welch, 2013; Strengers, Pink, \& Nicholls, 2019). A parallel body of work is concerned with the process, or how the design of change initiatives might be informed by social practice theory (Hoolohan \& Browne, 2020; Kuijer \& Bakker, 2015; Sahakian et al., 2021; Scott, Bakker, \& Quist, 2012; Vihalemm, Keller, \& Kiisel, 2015), in stark contrast to approaches which center on behavioral and individual change. Common to some approaches is a stage where people come together to reflect on social practices, by mapping the network of social and material elements that make up a practice (Vihalemm et al., 2015) and identifying 'change points,' towards more sustainable practices (Hoolohan \& Browne, 2020). These developments informed our research design in two ways. As an understanding of social change, we used social practice theory to guide our analysis of different initiatives that aim to reduce flying. In addition, practice theory informed the design of three focus groups with different sets of actors.

\subsection{Our Approach and Methods}

The research project is divided into two phases: In a first phase, we engaged in an exploratory review of mostly European initiatives that seek to reduce flying. First, we provided an overview of 37 initiatives (see Annex 1 in the Supplementary File), with information gathered from secondary sources and, when necessary, through email and video-call correspondence. This review led to a typology of initiatives, discussed below. Through discussions with the team (city representative, community energy association, and sociology research group at the university), we selected five initiatives to be further developed as case studies; this selection was made based on the diversity of audiences the initiative was addressed to (from individuals, to companies, to universities), the variety of travel purposes (leisure, professional, and academic), and the illustration of the different typologies of change initiatives. The case studies were developed through interviews with initiators.

In a second phase, and inspired by this exploratory work, we designed a series of World Café focus groups, where a selection of three initiatives were discussed and debated in groups, using a Futures Wheel methodology. The objective of the workshops was to ascertain the strengths and weaknesses of a proposed initiative, focused on two of the typologies identified in the first phase: 1 ) changes in systems, institutions, or infrastructures or 2) the promotion of alternatives, both understood as embedded in complex socio-material arrangements and thus related to everyday practices. We explicitly avoided any examples that focus on change solely through individual choice. Originating in the 1970s, Futures Wheel was recently used in the Swiss context and in a project interested in the implications of policy change initiatives towards energy transitions (Defila, Di Giulio, \& Schweizer, 2018). Actors come together to reflect on the first, second, and third level impacts of a proposed change initiative. In this process, the moderators at each table were able to bring in different 'elements of practices' in asking participants, for example, to reflect on how such a change initiative might relate to existing rules and regulations, social norms and expectations, investments in infrastructure, or people's skills and competencies.

Workshop participants were recruited through various means. In order to attract people of diverse backgrounds, we issued a call for participation through social networks, but also in cafés and schools in different neighbourhoods, and at train stations. We attracted students, researchers, and university administrative staff for the academic workshop, as well as airport ground staff, retirees, members of associations, employees in private companies, and public administrators, among others, for the other workshops. People were invited to complete a short questionnaire when signing up, generating some data on participant profiles. We achieved a gender balance and a good representation of different age groups, with people mostly between the ages of 31 and 50 years old (Figure 1).

Two workshops were hosted in a café in downtown Geneva, which offered break out rooms; due to confinement measures, the last workshop was hosted online. The three groups reflect the differences between travel for leisure $(n=14 ; 15.10 .2020)$ and professional travel ( $n=8 ; 3.11 .2020$ ), with a specific group on academic travel ( $n=14 ; 30.09 .2020$ ). When asked about flying frequency, most respondents take a flight two to four times per year, and only one person never flies (Figure 2). In Europe, most flights are short-haul (Figure 3). When asked how they planned to travel in the future, in relation to flying, half of the respondents would like to fly less often, reflecting a bias in workshop recruitment, while about a third would like to fly again or more frequently (Figure 4).

\section{Typology of Initiatives to Reduce Flying}

A total of 37 initiatives were identified, which aim at a partial or total reduction of air travel. Acting on different 


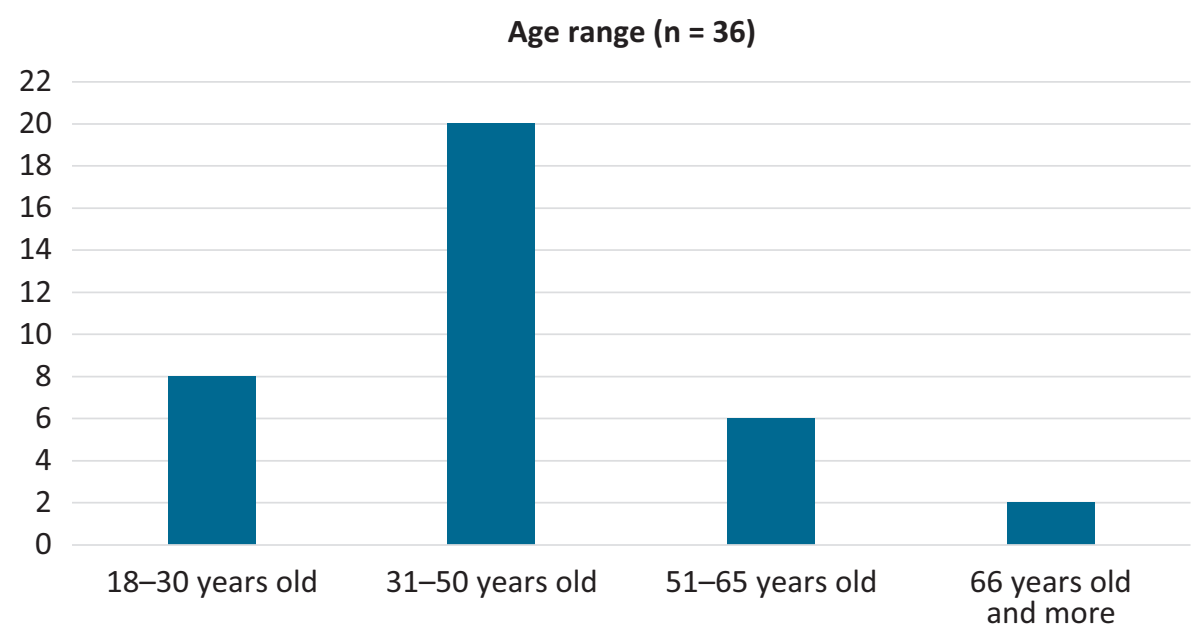

Figure 1. Age range of the workshop participants.

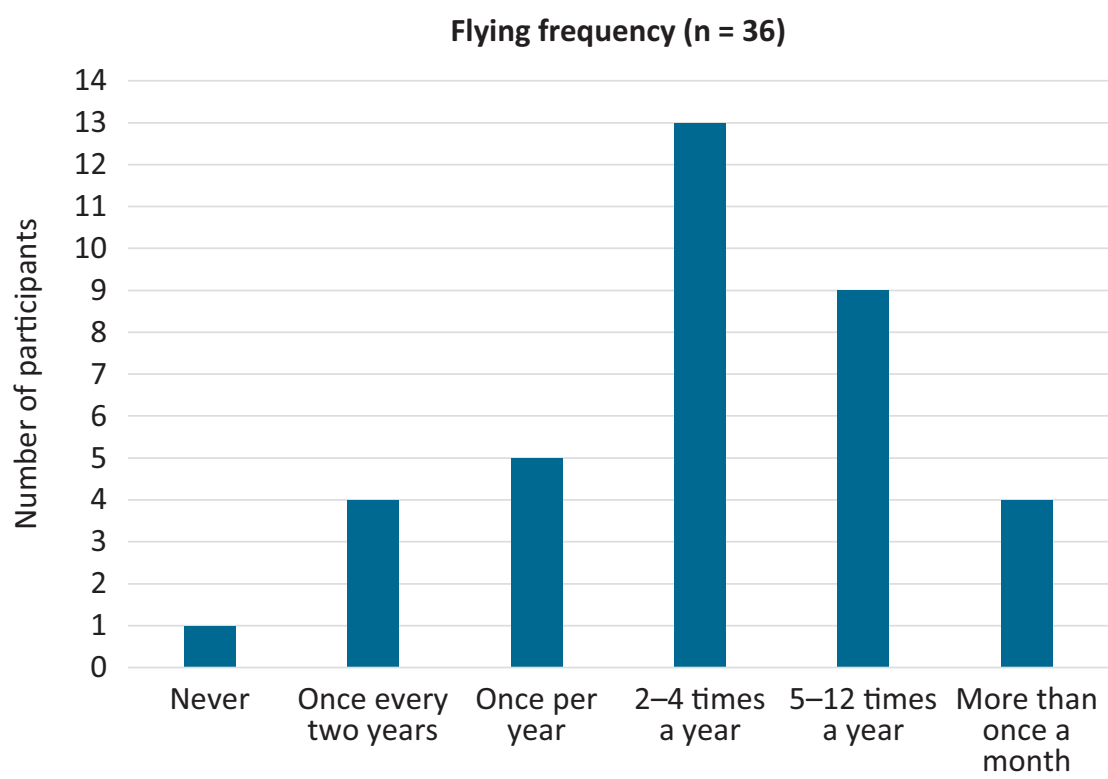

Figure 2. Flying frequency of the workshop participants.

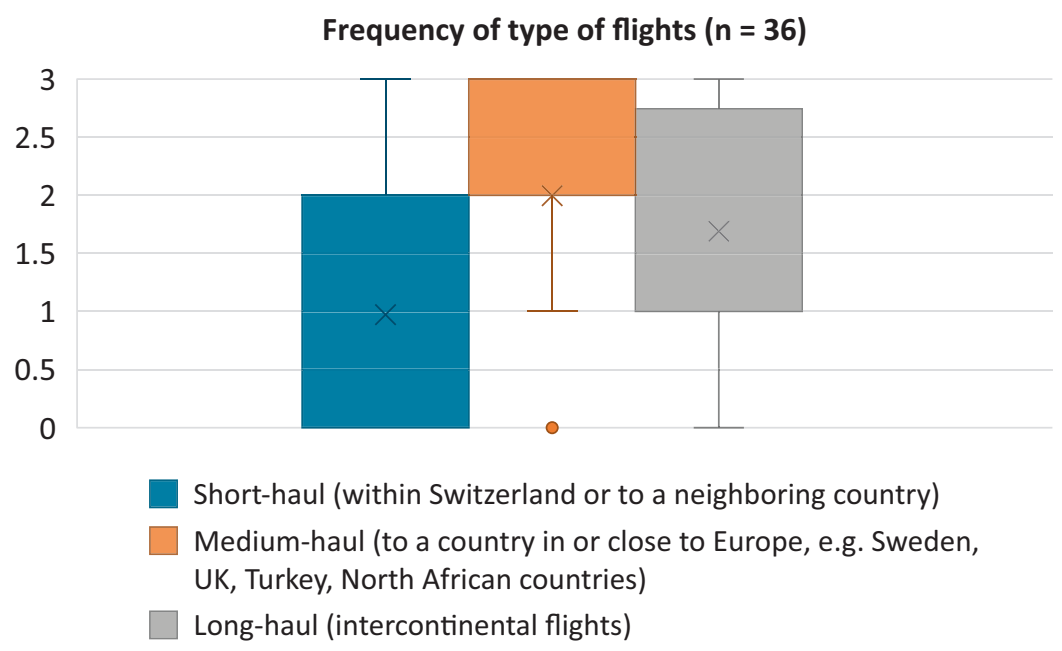

Figure 3. Flying frequency by type of flight for the workshop participants. 
In the future, you plan to $\ldots(n=36)$

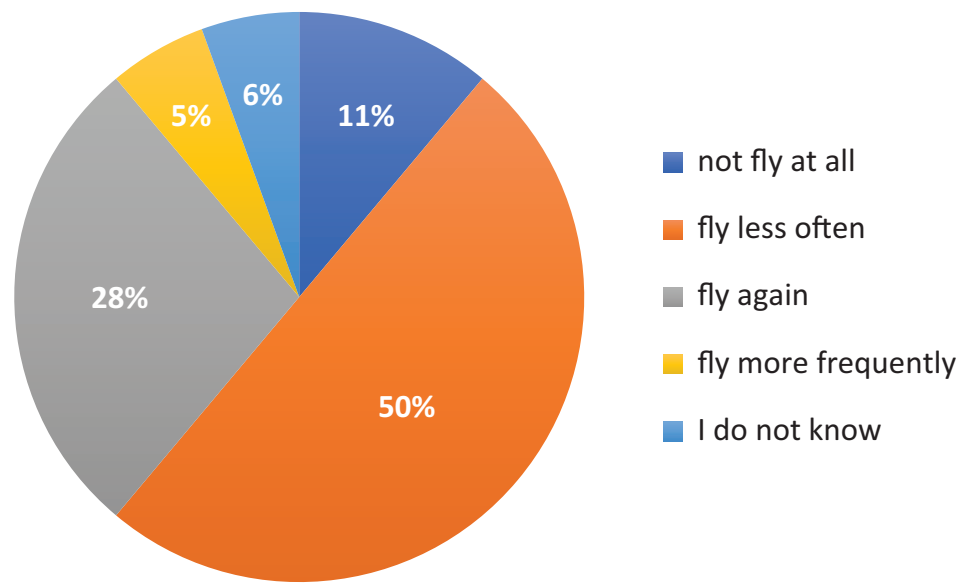

Figure 4. Expectations around future travel for the workshop participants.

scales (international, national, regional, for a city), they are distinguished by their target audience, their vision of change implied in the design of the initiative, and the tools put in place for their implementation. We present the distribution trends according to these categories in order to describe our sample, but in no way to generalise, as important biases arise from the selection we made, based on what data was readily available online. We also chose to group together various similar initiatives which counted as a single initiative, such as multiple carbon emission calculators, or similar university policies. Very few initiatives were launched before 2017, a turning point in media discourse in some countries (Ullström et al., 2020) or at least in actions to reduce flying: only nine initiatives (out of a total of 37) date from before 2017. On the basis of our review, we have drawn up a typology of initiatives based on the vision of change that their actions imply (Table 1). Although the initiators' vision of change is not reduced to a single type, they show a dominant inclination towards one of the following: change understood as being an individual choice, which is the dominant typology; change as happening at the level of systems, including constraints or encouragements across the system; and changes through the promotion of alternatives, oftentimes through collective efforts.

For each typology, various tools are used by the initiators (see Annex 2 in the Supplementary File). Among the 37 initiatives identified, one-way communication tools are often privileged, which see people as passive recipients of information, without any interactions (24.4\% of sample); two-way communications that ask something concrete of people are much less common (5.4\% of sample); the impact of such measures is difficult to observe and measure. Participation tools for engaging people at a collective level are also prominent, particularly through charters or petitions.

Behind each initiative, we have identified the following initiators: committed citizens, associations/NGOs, public figures, politicians, private or public companies, and institutions and academics. Initiators tend to change as projects evolved, but generally we found that certain actors tend to collaborate together-such as public institutions with academics, or citizens working with

Table 1. A typology of how change is understood for flying less initiatives $(n=37)$.

\section{Type 1: Change through individual choice (41\%)}

Initiatives that promote this form of change see individuals as the main actors towards reducing air travel, through an individual choice framing. Such initiatives focus on informing people (communication or education campaigns), as well as encouraging (bonus) or discouraging (carbon tax) air travel.

\section{Type 2: Systemic change, including constraints or encouragements (32\%)}

Initiatives that promote systemic change recognise that the decision to fly or not to fly is part of a broader context, including social practices, socio-technical systems, and involving institutional and regulatory frameworks. Individuals have the opportunity to change the system as consumers, actors, or engaged citizens.

\section{Type 3: Change through promoting alternatives, oftentimes through collective efforts (27\%)}

Change is expressed in the form of emerging alternatives, existing or new. These alternatives are put forward through demonstrations, or various forms of communication. Oftentimes, such change initiatives are supported through collective efforts. 
associations/NGOs, or associations/NGOs with public figures. Also, projects can be initiated by citizens who end up joining together in the form of an association to facilitate their legal, administrative, or organizational approach. We can nevertheless note that associations and NGOs, committed citizens, and institutions (to a lesser extent) are most often involved in initiatives that seek to promote flying less. When it comes to the target audience of such initiatives, most are aimed towards individuals, seen as change agents. Some consider governmental and institutional structures as responsible for instigating change, while others private entities to promote flying less. A small subset considers change as coming from a collective effort.

The initiatives are increasingly aimed at a particular type of travel, reflecting a growing understanding around the distinction between professional travel and leisure travel, and the different meanings around these practices. Even leisure travel needs to be further differentiated, to include the subset of people who travel specifically for visiting family and friends in distant countries, as opposed to travel for tourism and exploring new destinations, a topic we will come back to later (see Annexes 3 and 4 in the Supplementary File for target audiences and forms of travel targeted by the initiatives).

\section{Workshop Findings}

Inspired by the typologies and initiatives discussed above, the research team (City of Geneva representative, community energy association, academic partners) came together to select three main initiatives that would be discussed at each workshop in Fall 2020. All of the initiatives represent a form of systemic change, which could also include a promotion of alternatives (Types 2 and 3). By situating all initiatives in a social practice framing, participants were able to discuss how different elements of practices inter-relate-involving material arrangements in relation to mobility, the development of new competencies and skills, and the shifting of social norms related to why and in what way people travel. Through the Futures Wheel process, the change initiatives were studied in relation to how negative impacts could be attenuated, towards encouraging positive impacts, and doing so with a consideration for complex socio-material arrangements. A behavioural approach might have placed an undue emphasis on information campaigns, or bonus/malus approaches, which we felt would have been insufficient when accounting for the systems of provision that make some forms of consumption more normalized as desirable than others. In some instances, political economy considerations were clearly identified by the participants, such as the force of advertising for low-cost travel. Through a systemic approach to change, a negative impact identified in one area-such as reduced employment opportunities at the Geneva airport-could be tempered by other, positive impacts, such as increased employment in the rail sector or local tourism. Here, we discuss the findings and group together the two workshops on professional travel, followed by the one on leisure travel.

\subsection{Workshops on Professional Travel (Work-Related, with a Spotlight on Academic Travel)}

Three initiatives were chosen and presented in two workshops: a systemic change approach, whereby professionals come together in an institutional context to 1) sign a charter not to fly for any distance of under $1,000 \mathrm{~km}$, inspired by the 'Unter1000' initiative, launched by academics at German, Swiss, and Austrian universities (Scientist for Future, 2020) and two initiatives focused on supporting alternatives, involving 2) promoting virtual conferences and exchanges and 3) promoting slow travel, even for longer distances.

For not flying under $1,000 \mathrm{~km}$, participants saw time as the main constraint: For those who had families, this meant less time spent with family members at home, including children, and more time traveling for work and in transit. Another negative impact was the notion that some forms of travel may not be conducive to working in transit. To overcome these barriers, participants came up with ideas, including employers supporting child-care services for traveling parents. The train system was also seen as needing some form of change, either by ensuring comfortable spaces for working, or safe and comfortable overnight trains, with consistent internet connectivity. In accordance with the typologies developed above (Table 1), this relates to the need for systemic change-as it is not sufficient to change individual choices; the systems of provision around alternatives to train travel need to be tackled head on. In relation to social practices, changes in material arrangements would be necessary, but also social norms or collective understandings of how things ought to be-which would need to evolve within companies and universities towards valuing remote working, or being allowed to combine personal and family travel with professional travel. Participants highlighted the need for a consideration of work-life balance, if more time is dedicated to work through an increase in working time while travelling. Another main challenge identified was the price difference between the plane and alternative means of transport. Here, also, expectations might need to change, as employers must be agreeable to paying higher costs for travel in some cases. One imagined scenario devised by participants was to create an internal compensation scheme, whereby a carbon tax on flights would subsidize train travel. To limit the effect of people nonetheless preferring flights, such a strategy could be combined with an upper limit to flight travel for employees.

The second initiative on promoting alternatives focused on the development of online conferences and virtual exchanges. This initiative was seen as positive in several ways, as it would allow professionals to save time, reduce stress around travel (for some), and 
eliminate travel-related costs (transport and accommodation). However, there was concern around whether virtual meetings could replace informal contacts and the development of professional networks that are made possible in physical meetings (e.g., for younger versus more-established professionals). Participants came up with the idea of a new type of space, or a hub for virtual meetings, located in Geneva, and equipped with appropriate technologies and infrastructure for facilitating such meetings. Such a hub could host European satellite events around international conferences, for example. Ways of interacting informally would need to be encouraged in such settings, however, with attention paid to inequalities of access-or who can and cannot participate in such event formats. This idea takes the form of change through alternatives. In relation to practice theory, new skills and competencies might have to be developed in relation to this new socio-technical setting. An individual choice to attend a conference without engaging in air travel would not suffice: The alternative form of participation needs to be made available through this hub. For all virtual meetings, it is also essential to consider what material support people need-from computers to internet connectivity-and the energy intensity of such an alternative. In addition, employers could also support the development of new traveller skills, whereby people could determine if and when it is appropriate to travel physically, and for what type of meetingsupported by institutional guidelines.

The last 'promoting alternatives' initiative discussed was about supporting slow travel by privileging the use of trains, buses, bikes, ships, or shared means of transport, rather than flying. Here again, travel time and costs were mentioned, but time and energy spent on organizing travel was also emphasized by the participants. Non-flight travel is seen as complicated to implement, sometimes impossible depending on the destination, and particularly for long distance travel. The creation of a European-scale application to book all tickets at once, in relation to multi-modal transport (bus, trains, bikes, ride sharing, etc.) was mentioned, as well as service centres that are specialized in planning such forms of travel for professionals. Participants also felt that security, sanitary, and hygiene risks need to be accounted for. Some ideas that emerged underlined the need for employers to acknowledge the collective value of slow travel, by considering travel time as working time, but also giving visibility to people who travel this way, as a form of social recognition, or allocating extra holiday time for people to choose slow travel options over flights as a reward. From a social practice perspective, this means changing systems of provision for slow travel, but also collective conventions around the desirability of such forms of travel.

Participants were able to understand change in relation to social practices through evolving material arrangement, the acquisition of new skills, and competencies and changing social norms. Employers are seen as the primary change agents towards making 'flying less' a more compelling proposal, with the active engagement of a collective, as well as changing systems of provision. As public universities, such as the University of Geneva, grapple with the need to align their operations with ambitious carbon reduction targets, at the State and National levels, institutional conditions may be supportive towards efforts to reduce flying. Carbon monitoring is one first step in this direction and can demonstrate institutional support for alternative forms of travel, particularly when the results of a monitoring exercise are regularly made available and are accompanied by targets for planned reductions.

In Table 2, we present, in summary form, some of the impacts at multiple levels developed in the Future Wheel exercise, along with anticipated outcomes and ideas that emerged from that analysis.

\subsection{Workshop on Leisure Travel}

In the workshop on leisure travel, more emphasis was placed on what everyday people could do to reduce flying, through a practice-informed approach. The first initiative proposed was a voluntary challenge not to fly for one year, inspired by a similar initiative in Sweden. Flight Free World (2021) is a worldwide network, resulting from growing interest in the Swedish pledge launched in 2019 by We Stay on the Ground. Many recent initiatives aimed at reduction of flights (We Stay on the Ground, and the flygskam anti-flying movement) originated in Sweden and inspired other initiatives in Europe and elsewhere. As a systemic change initiative, the individual decision not to fly is part of a collective effort, supported by the media and organized at the level of a city or country. While flying less for leisure was generally seen as having more negative impacts than reducing flights for professional reasons, some positive effects were identified, such as developing local tourism, or enjoying 'staycations' and holiday-at-home practices. Participants recognized that agreeing to 'a year on the ground' could compel people to fly directly before or after this period. Thus, one negative impact would be the planning of elaborate future trips, once the challenge time is up. A second negative impact also raised was in relation to people who have family and/or close friends living in distant places. This underlines the need to distinguish between forms of leisure travel, as travel to support social relations is different from travel around acquiring new experiences (such as tourism to new destinations). One solution devised by participants was to create a challenge that would encourage people to visit nearby regions, countries, or capitals, encouraging visits to 'exotic' but nearby places - that would not merit flight travel. Another solution would be to provide options for reaching certain destinations without flying, which might involve a new platform for sharing such information if existing options are insufficient. Changes to the system of provision would be necessary to promote such solutions, for example through efforts by the City, 
Table 2. Reducing flights for professional travel: Different levels of negative or positive impacts and anticipated outcomes and ideas.

\begin{tabular}{lll}
\hline Impact level 1 & Impact level 2-3-4 & Anticipated outcomes and ideas \\
\hline$(-)$ More travel time & $\begin{array}{l}\text { (-) Difficult for people with } \\
\text { family/care responsibilities }\end{array}$ & $\begin{array}{l}\text { Assistance or support for family/care expenses } \\
\text { (childcare costs) }\end{array}$ \\
& $\begin{array}{l}\text { (+) More time to work during } \\
\text { travel }\end{array}$ & $\begin{array}{l}\text { Promote the train as a comfortable and isolated place } \\
\text { to work; promote night trains }\end{array}$ \\
\hline
\end{tabular}

(-) More expensive (+) Compensation for non-flight

Creation of a carbon tax scheme program in companies travel or institutions to tax flights, then redistribute the funds to support alternative transportation

$(+)$ Reduction in total amount of Promote both professional and private travel in a flights taken in a year combined way, so as to reduce overall costs

(+) More selectivity about (-) Loss of professional contacts, when to travel by plane from less travel

Support the development of new traveller skills to recognize if and when it is appropriate and important to travel, for what type of meeting, and what form of transport; provide institutional guidelines

(-) Slow travel is less prestigious than flying

Positive recognition for those who travel less; recognize and encourage employees who travel less, or who use other modes of transportation; give slow travel more visibility

$(+)$ More investments in virtual meeting technologies

Develop alternatives, such as virtual tools for meetings; create a dedicated conference hub in Geneva, or a network of hubs, where professionals can follow international conferences virtually

\begin{tabular}{lll}
\hline$(-)$ More complicated & $(-)$ Need time and skills/ & $\begin{array}{l}\text { Creation of a travel information office and a platform } \\
\text { combining all types of transport (bus, train, bikes, etc.) }\end{array}$ \\
to plan & knowledge for planning & combing
\end{tabular}

Note: Based on a Futures Wheel exercise, designed to identify 1st level impacts of a change initiative, followed by 2nd, 3rd, and 4th level impacts, as relevant.

travel agencies, associations, or social entrepreneurs, thus emphasizing the need for a systemic approach.

The second initiative discussed in the leisure travel workshop was a combination of not flying for distances under 1,000 km, but also only taking one long-haul flight every two years. The participants mentioned several direct negative effects regarding this initiative, such as missing out on the discovery of new places, or in the possibility of seeing family and close friends, along with time and cost constraints. However, the participants then arrived at several positive impacts related to this initiative, such as the intra-European exchanges that could emerge from more local or regional travel. They imagined that a 1,000 km radius would lead to the development of travel guides, encouraging local travel (an idea that applies well to Geneva, a city in central Europe). This would lead to the development of local tourism, or the creation of 'low-cost train routes' that would promote connections between key cities and regions in Europe. Towards this aim, it would be necessary to have an entity that would be responsible for cooperation and joint organization between the various railway companies, towards centralizing and simplifying information.
Here, the idea of promoting alternatives is put forward. Amidst these reflections, participants nonetheless commented on the fact that such initiatives are not sufficiently focused on reducing travel, in absolute terms, and that the directive to take a long-haul flight every two years might create a bias towards those who can afford such flights and, ultimately, serve to normalize the desirability of long-haul flights.

The third initiative discussed during the leisure travel workshop was also around the theme of slow travel. Some people noted that Geneva airport is an important economic actor in the area; for some, reducing flights meant reducing work opportunities around the airport. Train travel was seen as more expensive, more time intensive, and more complex to organise, as discussed earlier. This would lead to more time in transit, and less time with family members or friends. However, a positive effect was that people might take more time to travel, thus spending more time at their destination. One idea that came up was to transfer airport employees to the rail system, by acquiring new skills and towards jobs in train transport. Participants questioned whether train travel could lead to the same form of social distinction 
as flying, as traveling by air is seen as prestigious for some. Here again, participants noted that it would be important to not overcompensate the reduction of flying by traveling extensively through other means. Towards a shift in social norms, the participants suggested that solutions could be implemented to promote different meanings around family reunions or meetings with friends, such as virtual interactions, but also 'meeting half-way' (Table 3).

\section{Discussion and Conclusions}

Designing a change initiative to reduce flying is no small feat. While different initiatives are emerging around the

Table 3. Reducing flights for leisure travel: Different levels of negative or positive impacts and anticipated outcomes and ideas.

\begin{tabular}{lll}
\hline Impact level 1 & Impact level 2-3-4 & Anticipated outcomes and ideas \\
\hline $\begin{array}{l}(-) \text { Less employment } \\
\text { related to air-travel }\end{array}$ & $(+)$ Job creation elsewhere & $\begin{array}{l}\text { Promote trips in the back-country (not only big cities); } \\
\text { promote train travel-both leading to economic/job } \\
\text { opportunities }\end{array}$ \\
\end{tabular}

(-) Less distance travelled (+) Local tourism promotion Promote exoticism close to home (tourist guide); from Geneva, draw up with a compass a radius of $1,000 \mathrm{~km}$ to concentrate efforts for promoting slow travel

(+) More holidays-at-home or stay-cations, more relaxing and economical Promote the discovery of the area in your own backyard or close to home

(-) Less frequent visits of distant family and friends

Promote virtual meetings (with training for people

$(-)$ Less frequent trips without technological knowledge/skills)

(-) Less ability to cover

distances
(-) Less prestige from travel (fast and far)
(-) Less ability to 'acquire' new destinations

(-) Less ability to 'acquire' new experiences

(-) Socially desirable to travel, for status

$(-)$ More expensive travel (-) More inequalities between those who can afford alternatives and those who can not

(-) More time spent traveling

(-) Less time on location (visiting friends, family, sites)
Meet halfway through the trip

Propose challenges, for example: visit 3 capitals, 2 countries in one year, without flying

Promotion of fun trips by train, or thematic trips

Get influencers on board to normalize not flying for leisure

Propose and illustrate ten 'low-cost routes' by train; or promote ten recurrent lines on major axes

Provide subsidies or reward for non-flying travel

Encourage employers to allow remote-working while traveling for leisure, or provide an extra half day off for people who chose 'slow travel'

Provide faster, more comfortable, and secure infrastructures (night trains, fast trains, better lines and connections)

(-) More complicated (-) Less spontaneity to plan

Encourage the creation of a travel agency for travel without airplanes

(-) More time to organize Support the creation of a structure to organize cooperation between transport companies and travellers

$(+)$ Reduction of $\mathrm{CO}_{2} \quad(-)$ Should not be up to a emissions few heroic individuals

Make sure any initiative proposed is by the collective and for the collective

$(+)$ Socially desirable to have Encourage people to be more selective in their travel choices

$(+)$ More memorable and unique long-distance trips unique and memorable trips

Note: Based on a Futures Wheel exercise, designed to identify 1st level impacts of a change initiative, followed by 2nd, 3rd, and 4th leve impacts, as relevant. 
world, many seem to be focused on better informing individuals to incite changes in behaviour-a limited understanding of how change takes place, and one that stops short of accounting for the political economy in which air travel is promoted as a desirable form of transport-in the interest of powerful groups. Through a collaborative research-action project, we set out to understand how everyday people could be engaged in reflecting on flying less. By embedding change in social-material arrangements, we sought to complexify how different change initiatives might play out. A social practice approach to understanding mobility reveals both material and immaterial (but nonetheless rigid) challenges and opportunities, involving infrastructures and technologies, but also social norms and shared meanings around travel for both leisure and professional reasons. Participants were able to reflect on questions of equality and solidarity, in discussing in what way air travel might be necessary for certain people in some instances, or how train travel might be cost prohibitive for others, thus enlarging the scope of reflections beyond individual decision-making to collective efforts.

By involving citizens in such deliberations, new ideas emerged in terms of re-thinking how social practices can play out, towards the development of richer responses to public challenges. In this respect, the Futures Wheel exercise was particularly effective, as it entails going beyond immediate reactions (e.g., too costly, too time consuming, too complicated) towards more indirect impacts that can be positive and also lead to new ideas. In terms of limitations to the study, the workshop format and chosen initiatives are specific to the city of Geneva; the idea of not flying for under $1000 \mathrm{~km}$ would be very different on an island, for example. While rich qualitative data was gathered through workshops, a representative survey might be useful towards gauging support for select initiatives among the broader population. We also recognize that more work could be done to factor in wellbeing, or to understand how flying relates to human needs. Finally, the City asked us to explicitly focus on voluntary initiatives; we stopped short of studying the regulatory frameworks that might further reduce the appeal of flights. That being said, the Futures Wheel exercise did lead to more constraining ideas, that could be operationalised by the city administration through different modes of governing that are often used in combination-following Elofsson, Smedby, Larsson, and Nässén (2018) and building on Bulkeley and Kern's (2006) work on climate governance. For example, participants suggested an upper limit to long-haul flights per capita, or the creation of carbon tax and redistribution schemes as a way to support alternative forms of transport in Universities-and as part of a governing by authority strategy.

The City of Geneva has not yet chosen a way forward at the time of this writing, not least because of the uncertainty around travel in the current pandemic. Rather than chose one initiative, one way forward might be to include insights from across different initiatives towards a toolkit of possibilities, focusing on three main points. First, it is essential to differentiate and further complexify different forms of travel. Leisure travel for visiting family and friends who live in distant places represents a specific subset of leisure travel, for example, and one that needs to be handled differently from travel for tourism to visit new destinations. This relates to the need to account for diversity in travellers, as people with family members on different Continents are facing specific challenges when it comes to flying less. Efforts to reduce flights for professional travel must also further distinguish between trips that are seen as more necessary-for the promotion of early career employees, or for securing new supply chains, for example-versus those that can be effectively managed virtually. While the City of Geneva may not be in a position to influence employer policies, guidelines to support decisions on when flights are necessary or not may be useful, leading towards a strategy of governing by enabling (Elofsson et al., 2018).

Second, by engaging with a social practice perspective in the workshops design, we were able to move beyond the standard fare of providing more information as a way to incite individual behaviour change. The Futures Wheel exercises demonstrate the importance of changing material arrangements, for example in the alternatives to travel and the systems of provision that make some alternatives more appealing than others. This relates to governing by provisions (Elofsson et al., 2018), whereby the city supports air-travel alternatives. More investments could be made in promoting alternatives to individual travel for professional reasons at the City or State level, such as virtual conference hubs. But other dimensions of social practices were equally important, such as the meanings around flights, or the skills and competencies needed to travel through alternative means. Towards this aim, initiatives that bring more appeal to non-flight travel could be useful, as well as social learning opportunities-where citizens come together to learn and share new skills. Third, in terms of gaining insights from the different processes and tools described in Annex 1 in the Supplementary File, the workshop results suggest that the negative effects of any change initiative would need to be anticipated through two-way forms of communication such as the workshops-which could be expanded to a broader population through online platforms. Tools for influencer participation or for encouraging participation in communities of practice, such as the workplace or schools, could also be relevant.

This participatory dimension at the core of the project could also lead towards what Elofsson et al. (2018) have suggested as a new mode of local governance of greenhouse gas emissions for air-travel, the governing by agenda setting -building on work by scholars in urban governance. This governance strategy highlights "local government's capacity to act through various types of partnerships and other fora in order to build visions and influence policy and industry agendas beyond the 
local setting in a direction that supports the overarching goals set by local actors" (Elofsson et al., 2018, p. 580). Geneva, as home to international organizations, could set an example through its policies that might have a wider impact beyond the city.

The current Covid-19 pandemic also has implications for this study, as flying less is a given for many people experiencing reduced mobility, as is the case in Geneva at the time of this writing. If and when different forms of mobility are once again available to some, we might expect a rush to experience the speed of flight travel once again, or the desire to visit new places or old acquaintances. While virtual means of exchanges may have been uniformly promoted during the pandemic, they represent a poor substitute to physical interactions for many people. At the same time, being constrained to use virtual tools has contrived people into experimenting with such tools, making virtual exchanges more accessible and tangible as alternatives to physical travel but also showing the limits of solely online interactions.

Our participants may or may not have been interested in 'flying less' prior to attending the workshops, yet many expressed the need to re-think their approach to travel in terms of quantity (time spent, money spent, capitals visited, etc.) by the end of the workshops, towards reflecting on the need to reduce flight travel. This relates to a growing literature on sufficiency, which merits a public debate around how much travel is enough, for what purpose, and in relation to both environmental sustainability and human wellbeing (Toulouse et al., 2019). For this, more societal discussions could take place in our communities around 'how much is enough' and what a more qualitative approach to travel might look like. The social practice approach privileged in this project revealed the complexity of the challenge but also opportunities that were contextualized in relation to the everyday lives of citizens, towards a bottom-up public engagement process. Flying less is thus not solely an individual choice, but an opportunity for social learning that involves contesting established norms and supporting viable alternatives.

\section{Acknowledgments}

We are grateful to all of the participants who attended our workshops, and to the City of Geneva-Agenda 21Sustainable city unit for collaborating with us on this project. We would also like to thank the anonymous reviewers for their constructive comments, and the editors of this thematic issue for bringing us together. We are grateful for the feedback provided at a Sociological Lunch at the University of Geneva, where we presented this work, and particularly for the inputs of Jörg Balsiger.

\section{Conflict of Interests}

The authors declare no conflict of interests.

\section{Supplementary Material}

Supplementary material for this article is available online in the format provided by the authors (unedited).

\section{References}

Akenji, L. (2014). Consumer scapegoatism and limits to green consumerism. Journal of Cleaner Production, $63,13-23$.

Alcock, I., White, M. P., Taylor, T., Coldwell, D. F., Gribble, M. O., Evans, K. L., . . . Fleming, L. E. (2017). 'Green' on the ground but not in the air: Pro-environmental attitudes are related to household behaviours but not discretionary air travel. Global Environmental Change, 42, 136-147.

Balsiger, P., Lorenzini, J., \& Sahakian, M. (2019). How do ordinary Swiss people represent and engage with environmental issues? Grappling with cultural repertoires. Sociological Perspectives, 62(5), 794-814.

Büchs, M. (2017). The role of values for voluntary reductions of holiday air travel. Journal of Sustainable Tourism, 25(2), 234-250.

Bulkeley, H., \& Kern, K. (2006). Local government and the governing of climate change in the UK. Urban Studies, 43(12), 2237-2259.

Burian, I. (2018). It's up in the air: Academic flying of Swedish sustainability academic and a pathway to organisational change (Master thesis). Center for Sustainable Studies, Lund University, Lund, Sweden.

Chohan, U. W. (2019). The concept of the aerotropolis: $A$ review (CASS Working Papers on Economics and National Affairs) Islamabad: Centre for Aerospace and Security Studies. http://dx.doi.org/10.2139/ssrn. 3412543

Cohen, M. J., \& Murphy, J. (Eds.). (2001). Exploring sustainable consumption: Environmental policy and the social sciences. Oxford: Elsevier.

Cohen, S. A., Hanna, P., \& Gössling, S. (2017). The dark side of business travel: A media comments analysis. Transportation Research Part D: Transport and Environment, 61, 406-419.

Cohen, S. A., Higham, J., Gössling, S., Peeters, P., \& Eijgelaar, E. (2016). Finding effective pathways to sustainable mobility: Bridging the science-policy gap. Journal of Sustainable Tourism, 24(3), 317-334.

Czepkiewicz, M., Árnadóttir, Á., \& Heinonen, J. (2019). Flights dominate travel emissions of young urbanites. Sustainability, 11(22), 6340.

Defila, R., Di Giulio, A., \& Schweizer, C. R. (2018). Two souls are dwelling in my breast: Uncovering how individuals in their dual role as consumer-citizen perceive future energy policies. Energy Research \& Social Science, 35, 152-162.

Devaney, L., \& Davies, A. R. (2017). Disrupting household food consumption through experimental HomeLabs: Outcomes, connections, contexts. Journal of Consumer Culture, 17(3), 823-844. 
Elofsson, A., Smedby, N., Larsson, J., \& Nässén, J. (2018). Local governance of greenhouse gas emissions from air travel. Journal of Environmental Policy \&Planning, 20(5), 578-594.

Espino, C. M., Sundstrom, S. M., Frick, H. L., Jacobs, M., \& Peters, M. (2002). International business travel: Impact on families and travellers. Occupational and Environmental Medicine, 59(5), 309-322.

Federal Office of Civil Aviation. (2018). Monitoring de la compétitivité de l'aviation en Suisse 2018 [Monitoring of competitive aviation in Switzerland 2018]. Bern: Bern Federal Office of Civil Aviation. Retrieved from https://www.bazl.admin.ch/bazl/fr/ home/ofac/etudes-et-rapports.html

Federal Statistical Office. (2017). Comportement de la population en matière de transport: Résultats du microrecensement mobilité et transports 2015 [Population behaviour in terms of transport: Results from a micro-survey on mobility and transport 2015]. Neuchâtel: Federal Statistical Office.

Federal Statistical Office. (2019). Voyages de la population résidante Suisse en 2018 [Swiss resident population travel in 2018]. Neuchâtel: Federal Statistical Office.

Federal Statistical Office. (2020). Aviation civile Suisse 2019 [Swiss aviation 2019]. Neuchâtel: Federal Statistical Office.

Flight Free World. (2021). Flight free 2021. Flight Free World. Retrieved from https://flightfree.world

Hall, C. M., Gössling, S., \& Scott, D. (Eds.). (2015). The Routledge handbook of tourism and sustainability. Abingdon: Routledge.

Harvey, D. (1990). The condition of postmodernity: An enquiry into the origins of cultural change. Oxford and Cambridge, MA: Blackwell.

Hoolohan, C., \& Browne, A. L. (2020). Design thinking for practice-based intervention: Co-producing the change points toolkit to unlock (un)sustainable practices. Design Studies, 67, 102-132.

Ivancevich, J. M., Konopaske, R., \& DeFrank, R. S. (2003). Business travel stress: A model, propositions and managerial implications. Work \& Stress: An International Journal of Work, Health \& Organisations, 17(2), 138-157.

Jack, T. (2013). Nobody was dirty: Intervening in inconspicuous consumption of laundry routines. Journal of Consumer Culture, 13(3), 406-421.

Jensen, C. L., Goggins, G., Røpke, I., \& Fahy, F. (2019). Achieving sustainability transitions in residential energy use across Europe: The importance of problem framings. Energy Policy, 133, 110927.

Kantenbacher, J., Hanna, P., Cohen, S., \& Miller, G. (2018). Public attitudes about climate policy options for aviation. Environmental Science \& Policy, 81, 46-53.

Kaufmann, V. (2003). Re-thinking mobility: Contemporary sociology. London: Routledge.

Kroesen, M. (2013). Exploring people's viewpoints on air travel and climate change: Understanding incon- sistencies. Journal of Sustainable Tourism, 21(2), 271-290.

Kuijer, L., \& Bakker, C. (2015). Of chalk and cheese: Behaviour change and practice theory in sustainable design. International Journal of Sustainable Engineering, 8(3), 219-230.

Larsson, J., Elofsson, A., Sterner, T., \& Akerman, J. (2019). International and national climate policies for aviation: A review. Climate Policy, 19(6), 787-799.

Le Quéré, C., Jackson, R. B., Jones, M. W., Smith, A. J. P., Abernethy, S., Andrew, R. M., . . . Peters, G. P. (2020). Temporary reduction in daily global $\mathrm{CO}_{2}$ emissions during the COVID-19 forced confinement. Nature Climate Change, 10(7), 647-653.

Lee, D. S., Fahey, D. W., Skowron, A., Allen, M. R., Burkhardt, U., Chen, Q., . . . Wilcox, L. J. (2020). The contribution of global aviation to anthropogenic climate forcing for 2000 to 2018. Atmospheric Environment, 244, 117834.

Maniates, M. (2001). Individualization: Plant a tree, buy a bike, save the world? Global Environmental Politics, 1(3), 31-52.

Nevins, J. (2014). Academic jet-setting in a time of climate destabilization: Ecological privilege and professional geographic travel. The Professional Geographer, 66(2), 298-310.

Oswald, Y., Owen, A., \& Steinberger, J. K. (2020). Large inequality in international and intranational energy footprints between income groups and across consumption categories. Nature Energy, 5(3), 231-239.

Peeters, P. (2016). Tourism's impact on climate change and its mitigation challenges: How can tourism become 'climatically sustainable'? (Doctoral dissertation). Delft University of Technology, Delft, The Netherlands.

Peeters, P., Gössling, S., \& Becken, S. (2006). Innovation towards tourism sustainability: Climate change and aviation. International Journal of Innovation and Sustainable Development, 1(3), 184-200.

Randles, S., \& Mander, S. (2009). Aviation, consumption and the climate change debate: 'Are you going to tell me off for flying?' Technology Analysis \& Strategic Management, 21(1), 93-113.

Ritchie, H. (2020). Climate change and flying: What share of global $\mathrm{CO} 2$ emissions come from aviation? Our World in Data. Retrieved from https:// ourworldindata.org/co2-emissions-from-aviation

Sahakian, M. (2019). 'More, bigger, better' household appliances: Contesting normativity in practices through emotions. Journal of Consumer Culture. https://doi.org/10.1177/1469540519889983

Sahakian, M., \& Bertho, B. (2018). Exploring emotions and norms around Swiss household energy usage: When methods inform understandings of the social. Energy Research and Social Sciences, 45, 81-90.

Sahakian, M., Rau, H., Grealis, E., Godin, L., Wallenborn, G., Backhaus, J., . . . Fahy, F. (2021). Challenging social norms to recraft practices: A living lab 
approach to reducing household energy use in eight European countries. Energy Research \& Social Science, 72, 101881.

Sahakian, M., \& Wilhite, H. (2014). Making practice theory practicable: Towards more sustainable forms of consumption. Journal of Consumer Culture, 14(1), 25-44.

Schatzki, T. R. (1996). Social practices: A Wittgensteinian approach to human activity and the social. Cambridge: Cambridge University Press.

Scientist for Future. (2020). Voluntary commitment to refrain from short-haul business flights "I won't do it under 1000 km." Scientist for Future. Retrieved from https://unter1000.scientists4future.org

Scott, D., Gössling, S., \& Hall, C. M. (2012). International tourism and climate change. Wiley Interdisciplinary Reviews: Climate Change, 3(3), 213-232.

Scott, K., Bakker, C., \& Quist, J. (2012). Designing change by living change. Design Studies, 33(3), 279-297.

Shove, E., \& Pantzar, M. (2005). Consumers, producers and practices: Understanding the invention and reinvention of Nordic walking. Journal of Consumer Culture, 5(1), 43-64.

Spurling, N., McMeekin, A., Shove, E., Southerton, D., \& Welch, D. (2013). Interventions in practice: Re-framing policy approaches to consumer behaviour (Sustainable Practices Research Group, September 2013 Report). Manchester: University of Manchester.

State of Geneva. (2015). Plan directeur de l'énergie 2020-2030 [Energy master plan 2020-2030].
Geneva: State/Canton of Geneva. Retrieved from https://www.ge.ch/document/plan-climat-cantonalvolet-1

Strengers, Y., Pink, S., \& Nicholls, L. (2019). Smart energy futures and social practice imaginaries: Forecasting scenarios for pet care in Australian homes. Energy Research \& Social Science, 48, 108-115.

Toulouse, E., Sahakian, M., Lorek, S., Bohnenberger, K., Bierwirth, A., \& Leuser, L. (2019). Energy sufficiency: How can research better help and inform policy-making? In ECEEE Summer Study Proceedings (2-190-19; pp. 331-339). Stockholm: ECEEE.

Ullström, S., Nicholas, K., \& Stripple, J. (2020). Aspirational luxury, hypermobility, and staying on the ground: Tracing narratives of holiday air travel in Sweden, 1950-2020. Paper presented at 4th International Conference of the Sustainable Consumption Research and Action Initiative-SCORAI (Virtual), Stockholm, Sweden, and Boston, MA, USA.

Urry, J., \& Larsen, J. (2011). The tourist gaze 3.0 (3rd ed.). London, New Delhi, Singapore, and Los Angeles, CA: SAGE Publications.

Vihalemm, T., Keller, M., \& Kiisel, M. (2015). From interventions to social change: A guide to reshaping everyday practices. New York, NY: Routledge.

Warde, A. (2017). Consumption: A sociological analysis. New York, NY: Palgrave Macmillan.

Wilhite, H. (2016). The political economy of low carbon transformation: Breaking the habits of capitalism. London and New York, NY: Routledge.

\section{About the Authors}

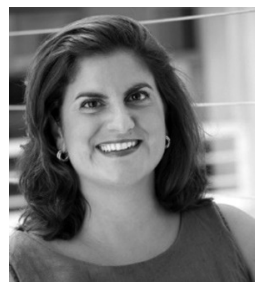

Marlyne Sahakian is Assistant Professor of Sociology at the University of Geneva, where she brings a sociological lens to consumption studies and sustainability. Her research interest is in understanding everyday practices in relation to environmental promotion, social equity, and social change. She is a Co-Founder of SCORAI Europe, a network for sustainable consumption research and action, and a member of ENOUGH, a network focused on sufficiency.

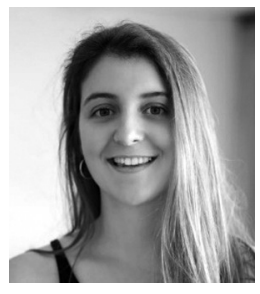

Malaïka Nagel is a Master's Student in Sociology at the University of Geneva, where she also has the dual role of Teaching and Research Assistant. She has been working on sustainable consumption issues with an affinity for social practice theories, an approach she brings in her current investigation on bioconstructions in Argentina, towards her future Master thesis.

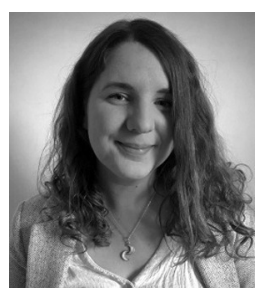

Valentine Donzelot is a Master's Student in Sociology at the University of Geneva. She worked as a Research Assistant at the Lucerne University of Applied Sciences and Arts, and at the Institute of Sociological Research at the University of Geneva as part of project on mobility in relation to sustainability. She is writing a master thesis on social relations within organisations following the Covid-19 pandemic. 


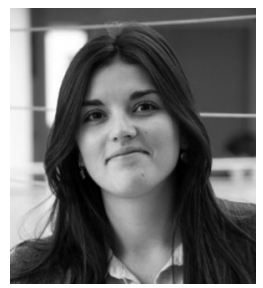

Orlane Moynat is a Research Assistant and PhD Candidate in Sociology at the Institute of Sociological Research at the University of Geneva. She has a Master's degree in Sociology from the University of Geneva, with a master thesis on degrowth and wellbeing. She is now working on a PhD thesis focused on sufficiency in relation to wellbeing theories, for the Swiss federal energy agency "Wellbeing, Energy Futures and Everyday Life" (WEFEL).

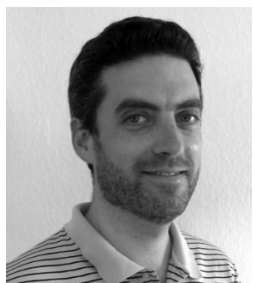

Wladyslaw Senn is Sustainability Projects Manager at terragir énergie solidaire, Geneva, Switzerland. His focus is on the implementation of local change-making projects with municipalities and utility companies at various levels around the topics of energy and resource sufficiency and efficiency. Wladyslaw is a Professional Trainer and Facilitator, using collective intelligence for building local capacity and transition towards low-carbon communities. 